\title{
A Comparative Research on the Characteristics of Civilian Staff Management in United States Army and Chinese Army
}

\author{
Lu Xinghuaa ${ }^{a}$ Zhang Xiaona ${ }^{b}$
}

\author{
Army Engineering University-Shijiazhuang Campus, Shijiazhuang , Hebei, China \\ aemail:Iu-xh163@163.com, bemail:907229834@qq.com
}

Keywords: US Army, Chinese army, Civilian staff, Management.

\begin{abstract}
This paper summarizes the current situation and characteristics of the management of the civilian staff in the US Army and the Chinese Army from multiple perspectives, and makes a comparative analysis of the differences between the civilian staff management of the two armies.
\end{abstract}

\section{美、中两军文职人员管理特点比较研究 \\ 卢兴华 ${ }^{\mathrm{a}}$ ，张孝娜 $\mathrm{b}$ \\ 陆军工程大学石家庄校区, 石家庄, 河北, 中国 \\ aemail:lu-xh163@163.com, bemail: 907229834@qq.com}

关键词: 美军; 中国军队; 文职人员; 管理

中文摘要. 本文从多个角度对美军和中国军队文职人员管理现状与特点进行了归纳, 并对两军文职人 员管理差异进行了比较分析。

\section{1. 引言}

美军实行文职人员制度有 200 多年的历史, 文职人员已经成为美国国防力量的重要组成 部分。中国军队根据自身建设需要, 近年来也建立了文职人员制度。对两军文职人员管理特 点进行比较分析, 可以有效把握军队文职人员管理的基本规律, 对借鉴经验做法, 不断改进 完善文职人员管理政策，具有十分重要的意义。

\section{2. 美军文职人员管理现状及特点}

\section{1 管理法规系统配套}

文官治军是美国建军的一项根本制度。根据这一制度, 美军文职人员既是联邦政府雇员, 又是美国武装力量的重要组成部分, 其职业定位十分明确。为了有效管理文职人员, 美国政 府和军队从不同层面制定了一系列管理政策, 形成了完备的法规体系。在国家层面, 美国国 会出台了多项法规, 包括：《联邦文职人员法》, 《文职雇员法》, 《公务员退休法》, 《职位分类 法》, 《绩效评估法》, 《联邦雇员团体人寿保险法》, 《工资改革法》, 《平等机会法案》, 《文职 人员制度改革法》, 《联邦雇员工资持平法》, 《联邦人事条例》等。美国国会规定, 军队使用 文职人员必须执行国会制定的统一法令, 在大政方针上不得自行其是。在军队层面, 国防部 和各军种部根据联邦政府的法规政策, 围绕文职人员招聘退休、岗位设置、使用管理、工资 
待遇、考核评价、奖惩激励等, 分别制定了有关规章, 以具体指导国防部和各军种文职人员 的管理。比如，国防部制定了《国防部文职人员管理制度: 文职人员战略人力资本计划》、《文 职人员手册》等，陆军部制定了《文职人员管理指南》、《文职人员合同管理》、《文职人员监 督》、《陆军部文职人员配置指南》、《陆军文职人员考评局》、《编制外文职人员政策》、《陆军 持续军事行动中文职人员的使用与管理》、《高级行政人员》、《美军陆军文职人员着装规定》 等, 这些法规主要涉及美军文职人员管理的具体规定和程序要求, 具有很强的操作性。

\section{2 领导体制健全完善}

根据《联邦文职人员法》, 美国联邦政府和军方都对文职人员履行领导职能。在政府方面, 国务院联邦人事管理办公室是政府管理文职人员的最高机关, 主要职责是完善相关法律法规, 监督各项法规的执行与落实，考核评估文职人员管理绩效，推进文职人员管理制度改革。政 府联邦紧急管理局、劳工部、人事管理局等担负美军文职人员的专项事务管理。联邦紧急管 理局负责人力资源的动员计划与管理工作，通过向政府其它部门提供计划信息，协调应急计 划制定, 控制国家人力分配流向, 以保障军事行动期间武装部队各军种以及联邦政府部门对 文职人员的需求。劳工部负责评估能用于军事的人力资源, 并将评估结果反馈给联邦紧急管 理局。在危机和战争动员时, 劳工部负责协调军地之间的人力动员计划, 满足国防单位对人 力的需求。人事管理局负责为联邦政府招募地方雇员, 在总统或国会宣布国家进入紧急状态 后, 担负向国防部提供文职人员、指导对联邦机构文职人员进行再分配工作，以满足行政机 构的人力需求。在军队方面, 国防部长办公厅是军队文职人员的政策指导机关, 对上就文职 人员来源、分配以及平战时使用等问题向总统提出建议, 对下负责指导各军种部的相关工作。 国防部内部，分管部队管理政策的助理国防部长负责对文职人员实施统一管理，其下设的一 名文职人员政策助理部长帮办，专门负责制定文职人员管理有关政策; 国防部分管人力、军 事设施和后勤的副部长负责汇总国防部文职人员缺额情况, 领导国防部文职人员的雇用和分 配保障工作。陆、海、空军的文职人员分别由各军种部人力与后备役事务助理部长统一管理, 各总部和司令部的人事副参谋长负责检查文职人员政策落实情况。此外，国防部和各军种人 事管理部门或司令部门都设立了文职人员管理局，具体负责文职人员的招聘、考核、选拔、 晋升、调动、福利以及战时或紧急状态下文职人员的动员与调配等工作。

\section{3 管理方式规范有效}

美军依法依规对文职人员实施管理，形成了比较规范的管理方式。在人员聘用上，美军 主要从即将退役的军人、社会人员、大学应届毕业生、政府离职人员四个渠道招聘文职人员, 受聘者按雇用性质分为临时雇员、合同雇员和职业文职人员三类。临时雇员使用期一般不超 过 1 年, 期满仍可继续任用, 但不能晋升和享受退休待遇。合同雇员使用期均为 1 年以上, 合同期满即退职; 若需继续雇用, 则须重新签订合同。合同雇员经 3 年工作后如继续雇用, 才可转为正式职业文职人员。在职级管理上, 美军将文职人员划分为 18 个级别, 各职级与军 人军衔有对应关系。其中, GS1-7 级相当于军队士兵级, 俗称蓝领雇员, 主要担负维修、保 养、设施管理等工作; GS8 级以上为白领雇员, 主要从事科研、教学、行政和秘书等工作; GS8-15 级相当于尉、校级军官, GS16-18 级相当于将级军官。在工作管理上, 美军实行绩效 管理制度, 建立了业务功绩与文职人员行政职务、功绩工资、考核评价和处分程序等进行相 关管理的规定。在福利待遇上, 美国《文职雇员法》规定, 美军文职人员的工资和福利水平 与联邦政府同级政府文职人员相同，薪金收入要低于同级军人。但为了吸引优秀人才为军队 服务, 美军区分不同情况对文职人员也给予一定的经济补贴。对于专业技术类文职人员，美 军给予的薪金反而比同级指挥军官高出 $20 \%$ 左右, 特别是聘用专家等特殊人才时往往给予更 高更优惠待遇，如享受教育补助、绩效奖金、生活消费补贴、分居补贴、交通补贴、高消费 地区购房和租房补贴等多项津贴补贴，约占工资构成的 $60 \%$ 。同时，美军对文职人员普遍给 予多种福利, 除享受与联邦政府人员同样的医疗保健、养老保险、人寿保险等福利待遇外, 
还享受现役军人的带薪休假、病休、军人服务社购买免税物品等福利。在战时管理上, 美军 规定战时紧急状态下文职人员在需要时必须接受雇用, 美军在近几场局部战争中都派遣了大 量文职人员走上战场。在伊拉克战争中，总统布什就把 “总统自由勋章” 授予了在战争中表 现优秀的文职人员。在着装管理上, 美军专门制定了《美国陆军文职人员着装规定》、《美国 空军文职人员着装与补贴规定》等规章, 要求在日常工作时大部分蓝领岗位人员必须统一着 制服，大部分白领岗位（科研、文秘等）不统一着制服，但要求着正装; 规定文职人员与现 役军人一起执行军事任务时, 文职人员军服需佩戴文职人员符号、工作任务符号和姓名牌三 种标志，还必须配备与军人相同的单兵防护装备。

\section{3.中国军队文职人员管理现状及特点}

中国军队实行文职人员制度起始于 2005 年。经过十年的实践，中国军队在文职人员队伍 建设上取得了很大成绩。目前军事院校、科研机构以及军队医疗机构等, 都招聘了一大批文 职人员从事专业技术工作, 成为军队建设一支有效支持力量。但从近年来的管理情况看, 中 国军队文职人员制度也暴露出许多亟待解决的问题。一是文职人员社会身份定位不明确。2005 年颁布的《中国人民解放军文职人员条例》将文职人员定位为军队聘用人员，与军队的关系 属于 “合同” 关系，人事档案存放在地方人才交流中心。这种定位意味着文职人员的社会职 业属性既不是军人也不是国家工作人员，而是服务于军队的 “合同人员”，因而导致许多文职 人员思想不稳定, 缺乏职业荣誉感, 普遍感到职业发展前途迷茫。二是文职人员以聘用普通 高校毕业生为主, 人员来源渠道单一，不利于吸引和获取更多的社会优秀人才为军队建设服 务。三是工资收入和生活待遇不够高。按照政策规定，文职人员的工资待遇基本与当地同职 级国家公务人员基本相同, 在军队内部文职人员与同级别军人同工不同酬, 并且在住房、医 疗、探亲、休假、疗养等方面, 文职人员基本没有优惠的福利待遇, 影响了文职人员的工作 积极性。四是职业发展受限, 文职人员聘任高级专业技术职务比较困难, 工作到 45 岁以后就 要面临被解聘等问题。

2015 年，以习近平为核心的党中央开启了新一轮军队体制编制和人力资源改革新征程。 着眼实现强军兴军目标和建立高效能的文职人员队伍, 2016 年国务院、中央军委颁布实施的 新的《中国人民解放军文职人员条例》 (以下简称新《条例》)，中央军委颁发了《关于改革期 间现役干部转改文职人员的实施意见》、《文职人员级别管理暂行规定》等一系列新的法规, 对文职人员管理政策制度进行了重大改革。主要特点是:

\section{1 明确了军队文职人员的身份定位}

新《条例》从两个方面对文职人员身份作了明确。在国家层面，明确文职人员依法享有 国家工作人员相应的权利, 履行相应的义务。在军队层面, 明确文职人员是在军队编制岗位 从事管理工作和专业技术工作的非现役人员，是军队人员的组成部分。这样明确文职人员身 份，反映了文职人员基本特点，为合理确定权利义务、制定相关政策制度提供依据。

\section{2 明确了文职人员的职能使命}

根据改革后对文职人员提出的使命要求, 参照国际通行做法, 新《条例》明确文职人员 平时履行相应岗位职责, 根据需要参加军事训练和非战争军事行动, 承担相应的作战支援保 障任务, 依法服现役。这样规定, 有利于规范文职人员岗位职责和力量运用, 有利于推进现 役力量与非现役力量分类建设, 提高军队整体作战能力。

\section{3 调整了文职人员的岗位类型划分和岗位等级设置}

适应改革后文职人员队伍担负的职能使命和岗位编制需求，新《条例》明确文职人员岗 位分为管理和专业技术两类。其中, 管理岗位是指担负领导职责或管理任务的工作岗位, 岗 位等级由高到低设置了 9 个等级, 即部级副职、局级正职、局级副职、处级正职、处级副职、 
科级正职、科级副职、科员、办事员; 专业技术岗位是指从事专业技术和专业技能工作，具 有相应专业技术、专业技能水平和能力要求的工作岗位，岗位等级设置保持不变。改革后的 一个突出变化是, 设置了文职人员领导岗位, 文职人员可以担任单位、机关部门或业务部门 领导职务。这样规定, 与军队现役干部有关制度设计相协调, 与国家工作人员岗位分类和设 置大体衔接，有利于推动文职人员队伍分类管理，提升队伍整体建设水平。

\section{4 拓宽了文职人员的来源渠道}

新《条例》保留了面向社会公开招录文职人员的政策，增加了直接引进和现役军人转改 两种文职人员招录方式。其中, 面向社会公开招考, 主要适用于新招录聘用科级正职以下管 理岗位的文职人员和中级以下专业技术岗位的文职人员；直接引进，主要适用于选拔高层次 人才和特殊专业人才; 现役军人转改文职人员, 主要适用从符合退役条件且拟作退役安置的 现役军人中选拔文职人员。文职人员来源渠道得到了有效拓展。

\section{5 提高了文职人员的工资和福利待遇}

新《条例》按照文职人员待遇高于地方同类人员、具有比较优势的思路，对相关制度作 了全面调整。在工资待遇上, 取消原来的属地化政策, 改以现役军官为参照系, 文职人员的 工资与职级同岗位现役军人待遇基本一致。在住房保障上，实行社会化、货币化保障政策， 文职人员可以租住用人单位的公寓住房，文职人员的住房公积金、住房补贴和房租补贴参照 现役军官政策确定的标准执行，符合规定条件的人员，军队可以增发住房补助。在社会保险 上，用人单位及其文职人员应当按照国家规定参加所在地职工基本医疗保险、失业保险、生 育保险, 缴纳保险费; 军队根据国家有关规定, 为文职人员建立补充保险; 平时看病享受社 保待遇, 军队给予医疗补助; 执行军事任务期间免费医疗。在福利抚恤上, 健康体检、探亲 休假、子女入托等普惠性福利待遇, 文职人员与现役军官同等享受; 平时抚恤执行国家工作 人员有关规定，参加军事任务伤亡的抚恤优待执行现役军人政策。

\section{6 建立完善了文职人员培训、考评、任用交流、等级调整、退出等管理机制}

根据国家有关规定，新《条例》将文职人员培训纳入军队人员培训体系，接受军事职业 教育，分级分类组织实施。明确文职人员的考核类型分为平时考核、年度考核、聘期考核， 以及试用期考核、晋升领导职务的任职前考核等, 并对考核内容、考核程序、考核结果等次 以及考核结果运用等作了原则规范。新《条例》在聘用制基础上增加了委任制用人方式, 参 照现役军官有关规定对文职人员的职务任免程序和权限作了明确; 增加了文职人员交流规定, 明确文职人员可以在用人单位内部交流，工作特别需要的也可以在本专业领域跨用人单位交 流。为使优秀人才留得住、不称职的走得出、退出军队后有保障, 新《条例》改进了退出政 策, 增加了辞职、辞退两种退出方式, 取消了原来的最高工作年龄限制, 明确文职人员退休 年龄统一按国家和军队规定执行; 文职人员退出军队后享受国家和军队规定的相应待遇, 转 移接续各种社会保障关系。

\section{7 规范了文职人员的教育管理}

新《条例》根据军队特殊要求和文职人员身份特点，对文职人员教育管理作了规范。其 中, 在思想政治教育、党团组织管理、安全保密、因公出境、档案管理等方面, 作出了与现 役军人相一致的规定。档案管理由原来的委托地方人才中介服务机构代理, 调整为由军队按 照规定权限统一管理。在入职宣誓、因私出境、人事争议处理等方面, 实行文职人员特有的、 与国家工作人员相衔接的管理制度。同时明确文职人员按军队统一规定着制式服装，佩戴相 应标志服饰。此外, 新《条例》还规定, 对作出突出贡献的文职人员, 按照国家和军队有关 规定给予表彰和奖励, 授予相应荣誉; 对违反军队纪律的文职人员按照军队有关规定给予处 分。 


\section{4. 对美、中军队文职人员管理制度的比较}

通过以上的介绍可以看到, 美军和中国军队在文职人员管理上各有特点。中国军队文职 人员制度建立起步晚, 在法规上制定上还不够完备、细化, 但就核心内容而言还是全面系统 的, 政策性、指导性十分明确。美军文职人员法规制度虽然配套完善, 但法规过于零散、政 策制度不够集中。比较来看, 美、中两军在文职人员管理上有很多相似之处, 包括: 文职人 员身份定位和录用渠道基本相同，都从低到高建立了军人和文职人员的职务等级对应关系， 都采取了诸多优惠待遇措施吸引保留文职人员, 都在军队专业技术岗位上大量使用文职人员 等等。这些相同点反映了世界各国军队在文职人员管理上的普遍做法与规律。同时，由于国 情不同, 两军在文职人员管理上也存在很多差异, 主要有:

\section{1 在军队建设管理中的主导作用存在差异}

美国实行文官治军制度, 文职人员在军队中居于决策和主导地位。美国国防部长、副部 长、助理部长以及他们的助手、三军部长及其副职等都由文职人员担任, 国防部和参谋长联 席会议 13 万人中文职人员多达 9.6 万人，其下属的 17 个业务局文职人员平均占 $70 \%$ 以上， 有的局全部为文职人员, 各军种部机关中文职人员所占比重也非常大。这些人员在军事决策、 预算、立法、协调等方面担负着非常重大的职责。中国军队是中国共产党领导的军队，按照 目前的法规, 文职人员虽然可以在军事机关中担任领导职务, 但主要岗位为行政副职, 对军 队建设所发挥的主导作用还十分有限。

\section{2 在军地之间的流动性上存在差异}

美国军队和政府都负有文职人员的管理职能，根据工作需要和军地岗位对文职人员的需 求，政府相关管理机构会根据实际情况发布相关人员需求信息，允许文职人员特别是行政管 理岗位的文职人员在军队和政府部门不同岗位进行流动任职。就中国军队而言, 文职人员可 以在军队体系内部进行调动, 但在军地之间的流动交流还没有出台相关政策。

\section{3 在吸引高水平人才的力度上存在差异}

按照新的《条例》及相关法规，中国军队给予文职人员的工资和福利待遇基本与现役军 人一致, 明显高于同职级地方公务员和事业单位人员, 这对一般文职人员而言是具有吸引力 的。但面对市场经济条件下争夺高层次人才日趋激烈的状况，目前军队所给予文职人员的工 作报酬和福利待遇对高水平专业技术人才来讲吸引力还很不够。美军为吸引和保留高级专业 技术人才, 在相关待遇上采取了很多特殊措施, 总体上经济与福利待遇要显著高于军队的指 挥军官, 这方面我军与美军还存在明显差距。

\section{5. 结束语}

文职人员制度是世界各国军队普遍采用的制度，对军队建设意义十分重大。比较分析美 中两军文职人员管理的制度做法, 目的在于能使我们从别人的做法与经验中获得启示, 进而 对我军建设提供有益参考与借鉴。

\section{References}

[1] Samuel P. Huntington, The Soldier and the State: The Theory and Politics of Civil-Military Relations, New York: Belknap Press, 2008.

[2] The State Council of People's Republic of China, The Central Military Commission of the People's Republic of China, The Civilian Staff Regulations of The PLA, 2015.

[3] Wu Gang, An analysis of the construction of civilian personnel in the United States Army, Research on the political and industrial theory of the army, vol. (16)6, pp.120-122, 2015. 
[4] Zheng Chunlin, Geng Minghua, To build an army that doesn't wear uniforms, Global Military, vol. 12, pp. 32-34, 2006.

[5] Civilian Staff in The US Army, The Academy of Military Sciences, Internal Document, 2010. 